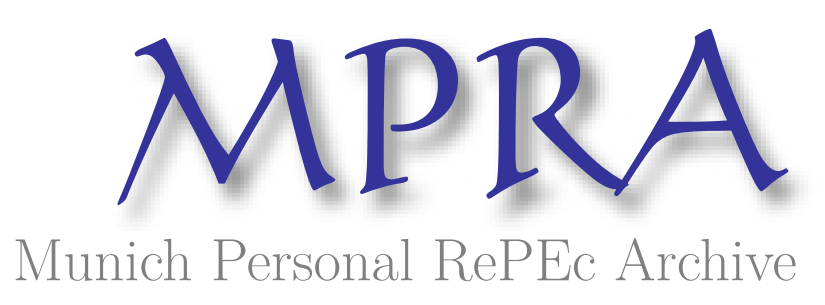

\title{
Disclosure Policies in Inspection Programs: The Role of Specific Deterrence
}

\author{
Makofske, Matthew
}

18 July 2020

Online at https://mpra.ub.uni-muenchen.de/102002/

MPRA Paper No. 102002, posted 23 Jul 2020 02:06 UTC 


\title{
DISCLOSURE POLICIES IN INSPECTION
}

\section{PROGRAMS: THE ROLE OF SPECIFIC}

\section{DETERRENCE}

\author{
Matthew Philip Makofske*
}

July 18,2020

\begin{abstract}
In inspection programs, policies of disclosing inspection performance promote greater compliance via general deterrence - i.e., by increasing the expected cost of regulatory violations. Yet, despite their growing popularity as regulatory aids, an unexamined matter is how specific deterrence-deterrence that follows from receiving punishment - might influence the effectiveness of disclosure policies. In Las Vegas, Nevada, food-service health inspections are scored numerically. Using a simple grading scale, scores are then coarsened into letter grades which restaurants must prominently display. There is, however, a wrinkle to this grading scale: establishments committing the same violation in consecutive inspections are downgraded one letter. By virtue of this downgrade rule, punishment assignment varies among identically scored inspections. Relative to establishments with identical sequences of prior inspection scores, I find that restaurants are assessed 17-27\% fewer demerits following a downgrade. This substantial specific deterrence effect has important implications for the design of disclosure policies; particularly, regarding the coarsening of numeric scores into letter grades.
\end{abstract}

JEL: K32, L15, I18

Keywords: disclosure, regulatory inspection, coarsening, letter grades, restaurant hygiene

*Department of Economics and Finance, Murray State University. 307 Business Building, Murray, KY, 42071. Email: mmakofske@murraystate.edu. Phone: (270) 809-4274. Declarations of interest: none. 


\section{Introduction}

Disclosure of regulatory violations is an increasingly popular supplement to conventional inspection programs. In general, disclosure is a relatively inexpensive regulatory tool, and has been found to improve restaurant hygiene (Jin and Leslie, 2003), drinking-water quality (Bennear and Olmstead, 2008), firm environmental ratings (Chatterji and Toffel, 2010), and worker safety (Johnson, 2020). Yet, by raising the stakes, disclosure can distort incentives toward manipulation or "gaming" behavior by producers (Dranove et al., 2003; Jacob and Levitt, 2003; Figlio and Getzler, 2006; Forbes et al., 2015), which underscores the importance of carefully designing disclosure policies.

When added to existing sanctions for noncompliance, disclosure of inspection performance enhances the punishment firms incur for detected regulatory violations. These enhancements promote compliance through general deterrence; that is, by increasing the expected cost of regulatory violations. However, despite their potential and popularity, an unexamined matter is how specific deterrence-deterrence that follows from actually being punished - might influence the effectiveness of disclosure policies as regulatory aids.

Recently, mandatory disclosure supplementing inspection programs has been especially common in food-service regulation. ${ }^{1}$ Food-service health inspections are often numerically scored, with detected health code violations carrying prescribed point deductions (from some base value) or demerits. Some public health agencies then disclose these scores. Others however, disclose only letter grades, which pool all scores within broad intervals. A subtle drawback of this coarsening is that potential specific deterrence goes unrealized, because detected violations only carry punishments if they push scores out of the top letter-grade interval. The significance of this drawback depends on if, and to what extent, specific deterrence exists in this setting. Yet, in general, estimating a counterfactual for those punished

\footnotetext{
${ }^{1}$ At https://www.foodsafetynews.com/restaurant-inspections-in-your-area/, Food Safety News maintains links to food-service inspection data which are made available by 236 different agencies spanning all 50 US states and the District of Columbia.
} 
complicates assessment of specific deterrence at the extensive margin. ${ }^{2}$ Exploiting a grading rule from a food-service-hygiene disclosure policy, I overcome this challenge, and find evidence of substantial specific deterrence.

The Southern Nevada Health District (SNHD) conducts food-service health inspections in the Las Vegas metropolitan area, and implements a disclosure policy. Inspections are scored numerically, with each detected violation carrying a prescribed demerit amount. Numeric scores are then coarsened to letter grades using a simple scale, ${ }^{3}$ and establishments are issued letter-grade placards which they must display until their next inspection. There is, however, a wrinkle to the basic grading scale: establishments that commit an identical violation across consecutive inspections are downgraded one letter. Consequently, following identically scored inspections (in the top letter-grade interval); some establishments incur punishment, while others do not.

Using SNHD inspections spanning January 2014 to March 2020; I estimate the effect of specific deterrence by exploiting this downgrade rule, which varies punishment among establishments that can be matched on recent detected compliance patterns. Holding exact sequences of (up to four) prior inspection scores fixed, I find evidence of significant and substantial specific deterrence at the extensive margin. Relative to comparable establishments that were not downgraded, establishments are assessed 17-27.1\% fewer demerits in inspections that follow a downgrade.

These findings further our understanding of a disclosure-policy design that is common in food-service regulation (where disclosure policies are widespread). ${ }^{4}$ When designing disclosure policies to supplement inspection programs, my results suggest specific deterrence as a significant channel for promoting compliance. Yet, coarsening numeric scores into letter grades misses out on much of this, because so many detected violations ultimately incur no

\footnotetext{
${ }^{2}$ At the extensive margin, specific deterrence is the effect of punishment relative to going unpunished.

${ }^{3}$ Scores of: 10 demerits or fewer receive an $A$ grade; 11 to 20 demerits receive a $B$ grade; 21 to 40 demerits receive a $C$ grade; and 41 or more demerits receive an $X$ grade and are temporarily closed.

${ }^{4}$ For instance, as of July 2020, 18 public health agencies share restaurant inspection information with Yelp.com. Of those agencies, 10 coarsen numeric scores prior to disclosure (6 report letter grades, and 4 simply report pass or fail.)
} 
punishment. Over this period, roughly $81 \%$ of SNHD inspections with violations still yielded the top letter grade (went unpunished). This particular drawback of letter-grade coarsening, while perhaps subtler than others, ${ }^{5}$ appears substantial.

\section{Background}

The SNHD was established jointly by Clark County, and the cities of Boulder City, Henderson, Las Vegas, Mesquite, and North Las Vegas, as the public health authority within those entities. Since 2005, a basic structure of scoring, grading, and disclosure has been in place; but scoring and grading criteria have changed several times. My analyses focus on the current policy regime, which began January 1, 2014. Since then, the regulations, scoring rules, and grading scheme have not changed.

Under the current regime, there are four categories of violation. The most serious, imminent health hazards, incur immediate temporary closure and fines. The SNHD defines the second most serious, critical violations, as "items directly related to the protection of the public from foodborne illness or injury". Major violations are items that "if left un-addressed may lead to a situation detrimental to public health". Least severe are violations of good food management practices (or good-practices violations). Critical, major, and good-practices violations, carry 5, 3, and 0 demerits, respectively. Imminent health hazards trigger an $X$ grade (the lowest possible).

On placards, inspection scores are coarsened into letter grades, which establishments must conspicuously display until their next inspection. Scores of: 10 demerits or fewer receive an $A$ grade; 11 to 20 demerits receive a $B$ grade; 21 to 40 demerits receive a $C$ grade. Establishments assessed 41 demerits or more are temporarily closed, fined, and given an $X$ grade. Most importantly (for this paper) is the downgrade rule: establishments committing

\footnotetext{
${ }^{5}$ Another drawback is that these systems distort incentives near letter-grade thresholds, which can ultimately compromise the integrity of inspections (see Makofske, 2020). Also, the further coarsening of an already one-dimensional metric (the numeric inspection score) limits the informational content of the disclosed signal, but does little to further simplify it.
} 
an identical critical or major violation in consecutive inspections are downgraded one letter.

\section{Data}

Data are from the Southern Nevada Health District (2020) website. ${ }^{6}$ Observations correspond to inspections and report (among other things): date, establishment, total assessed demerits, and letter grade. As seen in Appendix Table A1, the SNHD inspects many different establishment types, including some that are obscure. To focus on more common establishment types, primary estimates use only: bars/taverns, buffets, food trucks/mobile vendors, restaurants, and snack bars. The estimating sample spans January 1, 2014 to March 9, 2020. It consists only of routine inspections where the establishment's previous inspection involved at least one major or critical violation, and yielded 11 demerits or fewer. ${ }^{7}$

\section{Estimation Strategy}

I test for specific deterrence utilizing the downgrade rule, which varies the administration of punishment across identically scored inspections. Figure 1 demonstrates that, holding previous inspection score fixed, establishments perform better following downgrades. To control for other characteristics, I estimate a baseline linear model,

$$
\text { Dem }_{i, j}=\alpha \text { Downgrade }_{i, j-1}+\sum_{k \in K} \beta_{k} \times \mathrm{I}\left(\operatorname{Dem}_{i, j-1}=k\right)+\mathbf{X}_{i, j}^{\prime} \boldsymbol{\omega}+\epsilon_{i, j}
$$

where $D e m_{i, j}$ denotes total demerits assessed in the $j^{\text {th }}$ routine inspection of establishment $i$. Downgrade $_{i, j-1}$ is a binary variable indicating that establishment $i$ was downgraded in their previous inspection due to a consecutive identical critical or major violation. The estimating sample is restricted to observations where the demerit total from the establishment's previ-

\footnotetext{
${ }^{6}$ See https://www.southernnevadahealthdistrict.org/permits-and-regulations/restaurantinspections/developers/.

${ }^{7}$ These are the inspections where the downgrade rule may affect whether or not a punishment is incurred.
} 
ous routine inspection belongs to $K=\{3,5,6,8,9,10\} .{ }^{8}$ Table 1 summarizes this sample.

The vector of controls, $\mathbf{X}_{i, j}$, contains fixed effects for an inspection's weekday, month, year, and days elapsed (in 60-day intervals) since the establishment's previous inspection. Also included are fixed effects for the year-beginning with 2005 - of the establishment's first recorded inspection to account for differences in age/experience.

In estimating equation (1), $\hat{\alpha}$ compares detected compliance among establishments whose previous inspections yielded identical scores, but very different grades. In case the specific deterrence effect is partly persistent, I remove establishments from the estimating sample after one post-downgrade inspection. ${ }^{9}$ To identify specific deterrence, the underlying assumption is that: absent the downgrade rule and holding all controls fixed, expected $D e m_{i, j}$ would be the same for establishments that did, and did not, commit consecutive identical major or critical violations in inspection $j-1$.

Under the baseline specification, a threat to identification arises if Downgrade $_{i, j-1}$ differs conditional on compliance patterns prior to inspection $j-1$. Two particular differences would be problematic. First, if downgrades are more likely amid downward trends in demerits, then the continuation of these trends could be mistaken for specific deterrence. The other problematic issue would be if downgrades are more likely in worse-than-usual performances by establishments. Then, following the aberration, a return to their normal compliance levels might also be mistaken as specific deterrence.

To address these concerns, I augment the baseline specification and match establishments

\footnotetext{
${ }^{8}$ With good-practices violations assessed 0 demerits, inspection totals of 4 and 7 demerits are not possible. Prior to 2014, good-practices violations incurred 1 demerit. In observations where $D_{e m}, j-1$ is from an inspection prior to 2014, the demerit total is adjusted to what it would have been under the current scoring system.

${ }^{9}$ This ensures that scores from inspections where Downgrade $e_{i, j-1}=1$, are only compared to scores from establishments that had never been downgraded as of their $(j-1)^{t h}$ inspection.
} 
on more than their most recent prior inspection score. First, I estimate

$$
\begin{array}{r}
\text { Dem }_{i, j}=\alpha \text { Downgrade }_{i, j-1}+\sum_{(l, m) \in L} \beta_{(l, m)} \times I\left(\text { Dem }_{i, j-2}=l, \text { Dem }_{i, j-1}\right. \\
=m) \\
+\mathbf{X}_{i, j}^{\prime} \boldsymbol{\omega}+\epsilon_{i, j},
\end{array}
$$

where $I$ is a binary indicator, and $L$ is a set of 50 sequences, $\left(\operatorname{Dem}_{i, j-2}=l, D e m_{i, j-1}=\right.$ $m$ ), over which variation in Downgrade $_{i, j-1}$ is observed. That is, equation (2) estimates the immediate effect of having been downgraded, holding the sequence of $D e m_{i, j-2}$ and $D e m_{i, j-1}$ fixed. In separate specifications, establishments are matched on 206 sequences, $\left(\operatorname{Dem}_{i, j-3}, \operatorname{Dem}_{i, j-2}, \operatorname{Dem}_{i, j-1}\right)$; and then on 297 sequences, $\left(\operatorname{Dem}_{i, j-4}, \operatorname{Dem}_{i, j-3}, \operatorname{Dem}_{i, j-2}\right.$, $\left.\operatorname{Dem}_{i, j-1}\right)$.

\section{$5 \quad$ Results}

Column (1) of Table 2 reports estimates of equation (1) under a simple specification in which indicators of $D e m_{i, j-1}$ are the only included controls. In column (2), fixed effects are included for an inspection's weekday, month, year, and days elapsed (in 60-day intervals) since an establishment's previous routine inspection. In column (3), fixed effects for the year of an establishment's first recorded inspection are added. Standard errors are clustered by establishment, and reported in parentheses.

Across all three specifications, estimates demonstrate significant and substantial specific deterrence. Among the estimating sample's inspections where Downgrade ${ }_{i, j-1}=0$, establishments are assessed 6.5527 demerits on average. The specific deterrence effect estimated in the full specification, represents a $26.30 \%$ reduction in demerits relative to that average.

Columns (1), (2), and (3) of Table 3, report estimates that hold the sequence of an establishment's two, three, and four most recent inspection scores fixed, respectively. Across all three specifications, downgraded establishments are assessed significantly and substantially fewer demerits than establishments that were not downgraded, but followed the same 
inspection-score sequence up to that point. The coefficients in columns (1), (2), and (3), represent $27.10 \%, 23.21 \%$, and $17.02 \%$ reductions relative to means from their respective estimating samples when Downgrade $e_{i, j-1}=0$. The significant and substantial effect reported in column (3) - where the exact scoring sequence from four prior inspections is held fixed-largely alleviates concerns about Downgrade $_{i, j-1}$ correlating with prior compliance patterns. ${ }^{10}$

\section{Concluding Remarks}

These results have important implications regarding the design of disclosure policies to supplement inspection programs. As seen, specific deterrence can be a significant channel for promoting compliance. Numeric-score disclosure would likely make better use of this channel, because it punishes every detected violation. And while the punishments of posting 3 to 10-demerit scores are less severe than posting a $B$, about $81 \%$ of the routine inspections with violations over this period resulted in $A$ grades. As such, disclosing numeric scores in the $A$-grade range could have a substantial aggregate effect even by generating inspection-level specific deterrence that is a small fraction of the effect estimated here.

\footnotetext{
${ }^{10}$ Using all establishment types, Appendix Tables A2 and A3 report estimates corresponding to Tables 2 and 3. Estimates are very similar in sign, significance and magnitude.
} 


\section{References}

Bennear, L. S. and S. M. Olmstead (2008). The impacts of the "Right to Know": Information disclosure and the violation of drinking water standards. Journal of Environmental Economics and Management 56(2), 117-130.

Chatterji, A. K. and M. W. Toffel (2010). How firms respond to being rated. Strategic Management Journal 31(9), 917-945.

Dranove, D., D. Kessler, M. McClellan, and M. Satterthwaite (2003). Is more information better? The effects of "report cards" on health care providers. Journal of Political Economy $111(3), 555-588$.

Figlio, D. N. and L. S. Getzler (2006). Accountability, Ability and Disability: Gaming the System?, pp. 35-49.

Forbes, S., M. Lederman, and T. Tombe (2015). Quality disclosure programs and internal organizational practices: Evidence from airline flight delays. American Economic Journal: Microeconomics 7(2), 1-26.

Jacob, B. A. and S. Levitt (2003). Rotten apples: An investigation of the prevalence and predictors of teacher cheating. The Quarterly Journal of Economics 118(3), 843-877.

Jin, G. Z. and P. Leslie (2003). The effect of information on product quality: Evidence from restaurant hygiene grade cards. The Quarterly Journal of Economics 118(2), 409-451.

Johnson, M. S. (2020). Regulation by shaming: Deterrence effects of publicizing violations of workplace safety and health laws. American Economic Review 110(6), 1866-1904.

Makofske, M. (2020). Mandatory disclosure, letter-grade systems, and corruption: The case of los angeles county restaurant inspections. Journal of Economic Behavior and Organization 172(C), 292-313. 
Southern Nevada Health District (2020). Entire restaurant/food establishment database. Retrieved from https://www. southernnevadahealthdistrict.org/permitsand-regulations/restaurant-inspections/developers/. 


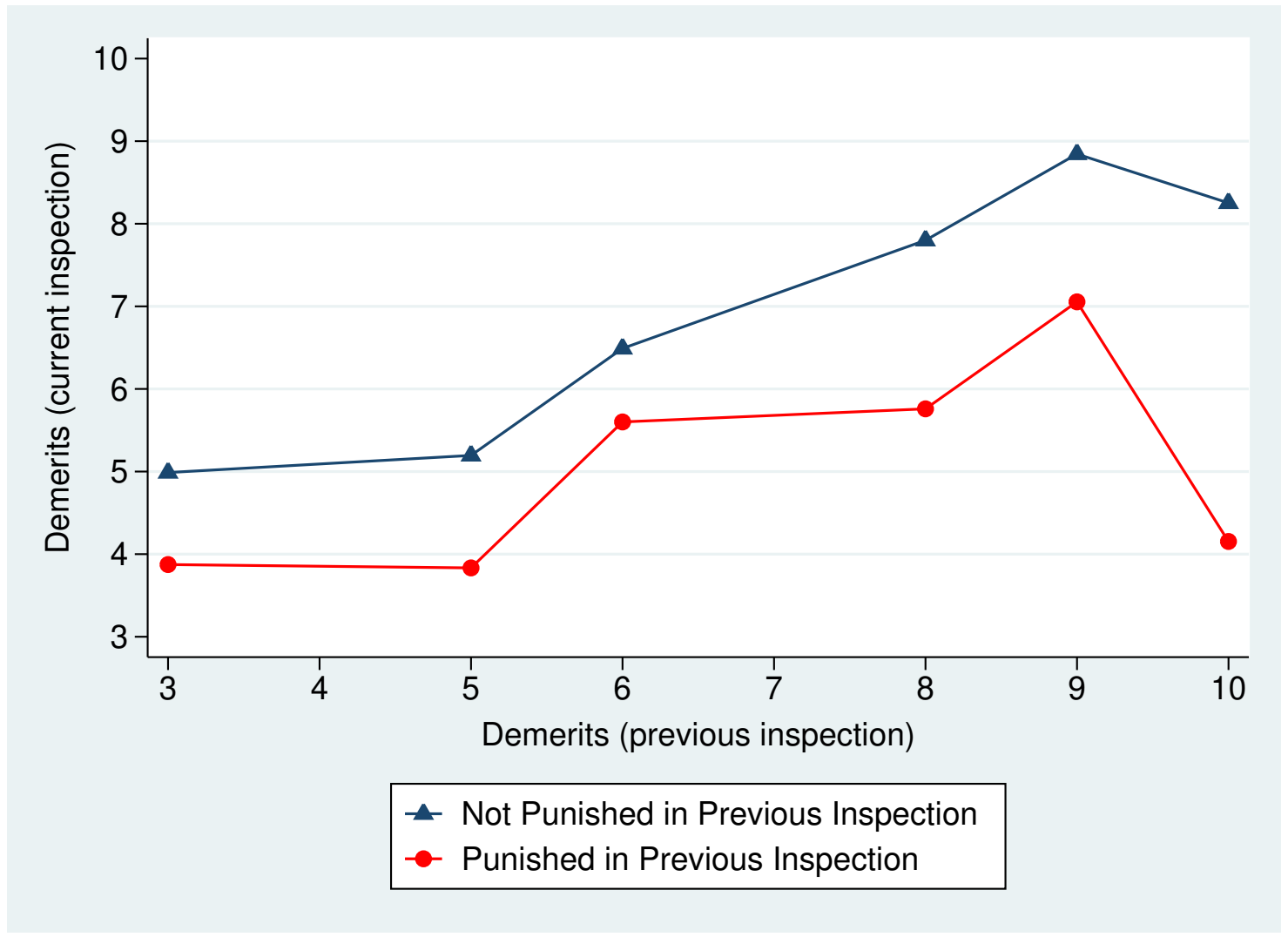

Figure 1: Specific Deterrence Following Downgrades

Average demerits in current inspections, by demerits and downgrade status from establishments' most recent previous inspections. Navy triangles mark averages among establishments that were not downgraded in their previous inspection, and red circles mark averages among establishments that were. Averages are from the 43,160 inspections in the primary estimating sample. 
Table 1: Estimating Sample Summary

\begin{tabular}{ccc}
\hline Dem $_{i, j-1}$ & Downgrade $_{i, j-1}=0$ & Downgrade $_{i, j-1}=1$ \\
\hline 3 & 14,377 & 111 \\
5 & 2,641 & 12 \\
6 & 9,158 & 203 \\
8 & 9,066 & 108 \\
9 & 6,384 & 219 \\
10 & 868 & 13 \\
\hline
\end{tabular}

Observations from the 43,160 inspections in the primary estimating sample. In total, 666 inspections (about $1.54 \%$ ) resulted in downgrades.

Table 2: Specific Deterrence: Baseline Estimates

\begin{tabular}{lccc}
\hline & \multicolumn{3}{c}{ Dem $_{i, j}$} \\
\cline { 2 - 4 } Variable & $(1)$ & $(2)$ & $(3)$ \\
\hline Downgrade $e_{i, j-1}$ & $-1.4800^{* * *}$ & $-1.7839^{* * *}$ & $-1.7283^{* * *}$ \\
& $(0.2158)$ & $(0.2169)$ & $(0.2170)$ \\
Dem $_{i, j-1}$ FE & & & \\
Day-of-Week FE & $\mathrm{Y}$ & $\mathrm{Y}$ & $\mathrm{Y}$ \\
Month-of-Year FE & $\mathrm{N}$ & $\mathrm{Y}$ & $\mathrm{Y}$ \\
Year FE & $\mathrm{N}$ & $\mathrm{Y}$ & $\mathrm{Y}$ \\
Days Elapsed FE $\dagger$ & $\mathrm{N}$ & $\mathrm{Y}$ & $\mathrm{Y}$ \\
Age FE $\ddagger$ & $\mathrm{N}$ & $\mathrm{N}$ & $\mathrm{Y}$ \\
\hline R-squared & 0.0516 & 0.0661 & 0.0692 \\
$\mathrm{~N}$ & 43,160 & 43,160 & 43,160 \\
\hline$* * * p<0.01$ & & &
\end{tabular}

OLS estimates of equation (1). The dependent variable is total demerits assessed in $j^{\text {th }}$ inspection of establishment $i$. The explanatory variable of interest indicates whether establishment $i$ was downgraded due to a consecutive identical major or critical violation in its $(j-1)^{t h}$ inspection. Standard errors, clustered by establishment, are reported in parentheses.

$\dagger$ These fixed effects indicate whether the days elapsed since an establishment's previous inspection are: $0-60,61-120,121-180,181-240,241-300,301-360,361-420,421-480,481-540$, or more than 540.

$\ddagger$ These fixed effects control for the first year in the raw data (going back to 2005) that an establishment was inspected. Establishments first inspected in 2017 or later are grouped together. 
Table 3: Specific Deterrence Estimates: Matching on Recent Inspection SeQUENCES

\begin{tabular}{llll}
\hline & \multicolumn{3}{c}{ Dem $_{i, j}$} \\
\cline { 2 - 4 } Variable & \multicolumn{1}{c}{$(1)$} & $(2)$ & $(3)$ \\
\hline Downgrade $_{i, j-1}$ & $-1.7111^{* * *}$ & $-1.4272^{* * *}$ & $-0.9335^{* * *}$ \\
& $(0.2173)$ & $(0.2247)$ & $(0.2759)$
\end{tabular}

Sequence Fixed Effects

\begin{tabular}{lccc}
\hline $\left.\operatorname{Dem}_{i, j-1}, D e m_{i, j-2}\right)$ & $\mathrm{Y}$ & $\mathrm{N}$ & $\mathrm{N}$ \\
$\left(\operatorname{Dem}_{i, j-1}, \operatorname{Dem}_{i, j-2}, \operatorname{Dem}_{i, j-3}\right)$ & $\mathrm{N}$ & $\mathrm{Y}$ & $\mathrm{N}$ \\
$\left(\operatorname{Dem}_{i, j-1}, \operatorname{Dem}_{i, j-2}, \operatorname{Dem}_{i, j-3}, D e m_{i, j-4}\right)$ & $\mathrm{N}$ & $\mathrm{N}$ & $\mathrm{Y}$ \\
& & & \\
Day-of-Week FE & $\mathrm{Y}$ & $\mathrm{Y}$ & $\mathrm{Y}$ \\
Month-of-Year FE & $\mathrm{Y}$ & $\mathrm{Y}$ & $\mathrm{Y}$ \\
Year FE & $\mathrm{Y}$ & $\mathrm{Y}$ & $\mathrm{Y}$ \\
Days Elapsed FE & $\mathrm{Y}$ & $\mathrm{Y}$ & $\mathrm{Y}$ \\
Age FE & $\mathrm{Y}$ & $\mathrm{Y}$ & $\mathrm{Y}$ \\
\hline R-squared & 0.1035 & 0.1107 & 0.1533 \\
$\mathrm{~N}$ & 33,888 & 18,967 & 6,880 \\
\hline$* * *$ & & &
\end{tabular}

OLS estimates. Sequence fixed effects account for the establishment's exact sequence of prior scores. Standard errors, clustered by establishment, are reported in parentheses. 


\section{A1 Appendix}

Table A1: Establishment Types in Raw Data

\begin{tabular}{lr}
\hline ESTABLISHMENT TYPE & NUMBER OF ESTABLISHMENTS \\
\hline Bakery Sales & 101 \\
Banquet Kitchen & 98 \\
Banquet Support & 38 \\
Bar/Tavern & 4,613 \\
Barbeque & 142 \\
Beer Bar & 14 \\
Buffet & 468 \\
Caterer & 424 \\
Childcare Kitchens & 54 \\
Concessions & 82 \\
Confection & 55 \\
Elementary School Kitchen & 264 \\
Farmer's Market & 54 \\
Food Trucks/Mobile Vendor & 995 \\
Frozen Meat Sales & 35 \\
Garde Manger & 90 \\
Grocery Store Sampling & 91 \\
Institutional Food Service & 142 \\
Kitchen Bakery & 103 \\
Main Kitchen & 13 \\
Meat/Poultry/Seafood & 219 \\
Pantry & 460 \\
Portable Bar & 85 \\
Portable Unit & 1,239 \\
Produce Market & 106 \\
Restaurant & 8,624 \\
Self-Service Food Truck & 66 \\
Snack Bar & 2,474 \\
Special Kitchen & 2,214 \\
Vegetable Prep & 53 \\
\hline 200, to nor of & 56
\end{tabular}

Since 2005, the number of establishments in each of the SNHD classifications. 
Table A2: Baseline Estimates: All Establishment Types

\begin{tabular}{lccc}
\hline \multirow{2}{*}{ Variable } & \multicolumn{3}{c}{ Dem $_{i, j}$} \\
\cline { 2 - 4 } & \multicolumn{1}{c}{$(1)$} & $(2)$ & $(3)$ \\
\hline Downgrade $_{i, j-1}$ & $-1.3463^{* * *}$ & $-1.5785^{* * *}$ & $-1.5347^{* * *}$ \\
& $(0.1833)$ & $(0.1837)$ & $(0.1838)$ \\
Dem $_{i, j-1}$ FE & & & \\
Day-of-Week FE & $\mathrm{Y}$ & $\mathrm{Y}$ & $\mathrm{Y}$ \\
Month-of-Year FE & $\mathrm{N}$ & $\mathrm{Y}$ & $\mathrm{Y}$ \\
Year FE & $\mathrm{N}$ & $\mathrm{Y}$ & $\mathrm{Y}$ \\
Days Elapsed FE & $\mathrm{N}$ & $\mathrm{Y}$ & $\mathrm{Y}$ \\
Age FE & $\mathrm{N}$ & $\mathrm{N}$ & $\mathrm{Y}$ \\
\hline R-squared & 0.0544 & 0.0674 & 0.0699 \\
$\mathrm{~N}$ & 54,689 & 54,689 & 54,689 \\
\hline$* * * p<0.01$ & & &
\end{tabular}

OLS estimates of equation (1) with the sample including all establishment types. Standard errors, clustered by establishment, are reported in parentheses. 
Table A3: Matching on Recent Inspection Sequences: All Establishment TYPES

\begin{tabular}{|c|c|c|c|}
\hline \multirow[b]{2}{*}{ Variable } & \multicolumn{3}{|c|}{$D_{e} m_{i, j}$} \\
\hline & (1) & $(2)$ & (3) \\
\hline Downgrade $_{i, j-1}$ & $\begin{array}{l}-1.6305^{* * *} \\
(0.1845)\end{array}$ & $\begin{array}{l}-1.3938^{* * *} \\
(0.1914)\end{array}$ & $\begin{array}{l}-0.9696 * * * \\
(0.2370)\end{array}$ \\
\hline
\end{tabular}

Sequence Fixed Effects

\begin{tabular}{lccc}
\hline$\left(D e m_{i, j-1}, D e m_{i, j-2}\right)$ & $\mathrm{Y}$ & $\mathrm{N}$ & $\mathrm{N}$ \\
$\left(\operatorname{Dem}_{i, j-1}, D e m_{i, j-2}, D e m_{i, j-3}\right)$ & $\mathrm{N}$ & $\mathrm{Y}$ & $\mathrm{N}$ \\
$\left(\operatorname{Dem}_{i, j-1}, D e m_{i, j-2}, D e m_{i, j-3}, D e m_{i, j-4}\right)$ & $\mathrm{N}$ & $\mathrm{N}$ & $\mathrm{Y}$ \\
& & & $\mathrm{Y}$ \\
Day-of-Week FE & $\mathrm{Y}$ & $\mathrm{Y}$ & $\mathrm{Y}$ \\
Month-of-Year FE & $\mathrm{Y}$ & $\mathrm{Y}$ & $\mathrm{Y}$ \\
Year FE & $\mathrm{Y}$ & $\mathrm{Y}$ & $\mathrm{Y}$ \\
Days Elapsed FE & $\mathrm{Y}$ & $\mathrm{Y}$ & $\mathrm{Y}$ \\
Age FE & $\mathrm{Y}$ & 0.1294 & 0.1513 \\
R-squared & 0.1112 & 26,110 & 9,262 \\
N & 44,220 & &
\end{tabular}

$* * * p<0.01$

OLS estimates from all establishment types. The sequence fixed effects account for the establishment's exact sequence of scores. Standard errors, clustered by restaurant, are reported in parentheses. 